\title{
FTA, Customs Union or Unilateral Trade Policy? Final Status Options for "the West Bank and Gaza"
}

\author{
Maurice Schiff \\ The World Bank
}

\begin{abstract}
This paper considers regional and unilateral trade policy options for the West Bank and Gaza (WBG). It examines the welfare implications of a free trade agreement (FTA) with Israel, a customs union (CU) with Israel, and a nondiscriminatory trade policy (NDTP). The analysis captures the fact that the WBG is landlocked, that it has a large trade deficit with Israel, and that smuggling takes place between them. The paper concludes that i) a NDTP is unambiguously superior to a FTA with Israel; but ii) the WBG should only pursue a NDTP if the policy is open, transparent, and enforced by a credible lock-in mechanism; otherwise, a CU with Israel may be preferable, especially if trade and other taxes are shared more equitably.
\end{abstract}

- JEL Classifications: F13, F15, O53

- Key words: West Bank-Gaza, Customs union, FTA, Unilateral liberalization.

\section{Introduction}

Until 1993, Israel exercised full authority over the West Bank and Gaza (WBG), including over the $W B G$ trade policy. In 1993, the Israeli government and the Palestinian Authority ( $P A$ ) signed the Declaration of Principles (known as the Oslo accord). This provided the PA with authority over parts of $W B G$ and required the establishment of economic relations between Israel and the PA. The 1994 Protocol on Economic Relations (referred to as the Paris Protocol) laid out transitional economic arrangements for the period until the final status stage between Israel

*Corresponding address: Doctor Maurice Schiff, The World Bank, 1818 H. St. NW, Washington DC 20433, USA Tel.: +202-473-7963, Fax: +202-522-1159, Email: mschiff@worldbank.org (C2003-Center for International Economics, Sejong Institution, All Rights Reserved. 
and the Palestinians. This paper examines what economic arrangements would best serve $W B G$ once that stage is reached. The focus is on trade policy, both with Israel and with the rest of the world.

The $W B G$ is landlocked, highly economically integrated with Israel which is its largest trading partner, runs a large trade deficit with Israel, and its trade with Israel is subject to smuggling. These conditions affect the calculus of the costs and benefits of the $W B G$ 's policy options. The analysis takes these conditions explicitly into account.

The various policy options to be considered by $W B G$ have economic implications as well as implications with respect to sovereignty and political control. As far as trade policies with Israel are concerned, a customs union $(C U)$ provides less political control for $W B G$ than a free trade agreement (FTA), and an FTA provides less political control than a non-discriminatory trade policy (NDTP). ${ }^{1}$ A NDTP treats Israel the same as any country with which $W B G$ has no preferential agreement (thus charging Israel the MFN tariff). ${ }^{2}$ In addition to trade policy, a brief section examines currency issues.

An early study on $W B G$ by Fischer et al. (1994) examines labor, fiscal, monetary, financial and foreign aid aspects and provides a set of sensible policy recommendations. In trade, it recommends integration of Israel, $W B G$ and Jordan, with an FTA in goods, services, capital and technology. The recommendation is based on the view that free trade provides the best opportunities for growth in the region.

Though this advice may seem to make eminent sense, it should be recalled that FTAs as well as other types of regional agreements are "second-best"-type policies, and assessing the welfare impact of moving from one second best (the existing $C U$ ) to another one (the recommended FTA) is never simple. First, an FTA between Israel, $W B G$ and Jordan is not the same as free trade since trade under an FTA is not free with excluded regions. Second, implementation of an FTA entails a number of complexities that require careful examination.

The $W B G$ currently has a (modified) customs union $(C U)$ with Israel. This paper examines various options for the $W B G$ 's trade relations with Israel and the

${ }^{1}$ A FTA frees trade between the member countries of the FTA while each maintains its own trade policy with respect to excluded countries. A $C U$ also frees trade between member countries but constrains them to a common external trade policy. The latter typically entails detailed negotiations between them and implies a greater loss of sovereignty than a FTA. NDTP implies that a country determines its trade policy unilaterally and provides no preferential access to anyone.

${ }^{2}$ The MFN or most-favored-nation principle, the basic principle underlying the GATT and the WTO, states that a country will treat all countries equally from the viewpoint of access to its markets, i.e., it will not provide preferential access to any country. 
rest of the world. The alternative trade policy options for $W B G$ that are considered are:

i) the continuation of the $C U$, with or without improved sharing of revenues from tariffs and other trade taxes;

ii) a free trade agreement ( $F T A)$ with Israel; and

iii) a non-discriminatory trade policy $(N D T P)$.

Table 1 summarizes the costs and benefits of the various trade policy options. The calculations of costs and benefits are based on regional integration theory, official statistics where available, and a few assumptions where official statistics are not available (as for smuggling). These are explained in detail at each step of the calculations. All figures are for 1998, the most recent year with the most complete data set (from the WTO Trade Policy Review for Israel).

The paper concludes that the trade regime of conditional non-discrimination ("conditional NDTP") is likely to provide the greatest economic benefits to the $W B G$. Thus, the scheme that is viewed as economically most beneficial also provides $W B G$ with the greatest degree of political control. The policy is referred to as a "conditional NDTP" because its choice is conditional on the $P A$ liberalizing the trade regime of $W B G$ and applying a number of restrictions in order to prevent any backsliding of its trade policy, including binding tariffs at applied levels at the WTO and implementing credible mechanisms to prevent the use of anti-dumping and other restrictive non-tariff measures.

Whether such conditions will actually be met in the final status stage is impossible to predict. In fact, it is not even known when (or if) the final status stage will be reached or what political institutions will be put in place at that time, let alone the nature of $W B G$ 's economic relations with Israel and the rest of the world or any details of such relations. Nevertheless, examining the implications of the various policy options for $W B G$ is a useful exercise because it helps clarify the economic impact of existing relations between $W B G$ and Israel, and the analysis under alternative $M F N$ liberalization conditions can constitute one of the bases for discussion and negotiation when the time comes.

The NDTP option is unlikely to be optimal if these liberalization conditions are not met. In that case, because of the discipline it provides, a $C U$ with Israel may be preferable, assuming trade and other taxes are shared more equitably, a likely scenario in a final status arrangement. Contrary to the conclusion reached in 
Table 1. WBG Loss of $C U$ and FTA as Compared to $N D T P^{*}$ (1998 data, in \$ million) ${ }^{\#}$

\begin{tabular}{|c|c|c|c|c|c|}
\hline \multicolumn{6}{|c|}{ 1.0 Customs Union $(\mathrm{CU})$} \\
\hline & 1.1 & \multicolumn{4}{|l|}{ Losses } \\
\hline & & 1.1 .1 & \multicolumn{3}{|l|}{ Indirect Imports } \\
\hline & & & \multicolumn{2}{|c|}{ - Loss of tariff and purchase tax revenues } & 133 \\
\hline & & & \multicolumn{2}{|c|}{ - Excess leakage of VAT revenues } & $\underline{41}$ \\
\hline & & & \multicolumn{2}{|l|}{ Total } & 174 \\
\hline & & 1.1 .2 & \multicolumn{3}{|l|}{$\underline{\text { Transfers }}$} \\
\hline & & & \multirow[t]{3}{*}{ - No Smuggling: } & Loss & 200 \\
\hline & & & & Gain & 64 \\
\hline & & & & Net & 136 \\
\hline & & & - Smuggling: & Loss & 160 \\
\hline & & & \multirow[t]{2}{*}{ Loss } & Gain & 64 \\
\hline & & & & Net & 96 \\
\hline & & & \multirow[t]{2}{*}{ - Total Losses: } & No Smuggling & 310 \\
\hline & & & & Smuggling & 270 \\
\hline & 1.2 & \multicolumn{4}{|l|}{$\underline{\text { Gains }}$} \\
\hline & & \multicolumn{2}{|c|}{ Border Costs Savings } & 48 & \\
\hline & 1.3 & \multicolumn{4}{|c|}{ Net Loss } \\
\hline & & \multicolumn{2}{|c|}{ No Smuggling } & 262 & \\
\hline & & \multicolumn{2}{|c|}{ Smuggling } & 222 & \\
\hline \multirow[t]{6}{*}{2.0} & FTA & & & & \\
\hline & 2.1 & $\underline{\text { Losses }}$ & & & \\
\hline & & 2.1 .1 & \multicolumn{3}{|l|}{$\underline{\text { Transfers }}$} \\
\hline & & & - No Smuggling: & 136 & \\
\hline & & & - Smuggling: & 96 & \\
\hline & & 2.1 .2 & \multicolumn{3}{|l|}{$\underline{\text { Rules of Origin }}$} \\
\hline- & & & \multicolumn{3}{|c|}{ - Cost to exporters $=3-5 \%$ of } \\
\hline- & & & \multicolumn{3}{|c|}{ - import value from all } \\
\hline- & & & \multicolumn{3}{|c|}{ - FTA partners: 84 to 140} \\
\hline- & & & \multicolumn{3}{|c|}{ - Other costs (trade diversion, and other): $\chi$ (not quantifiable) } \\
\hline & & 2.1 .3 & \multicolumn{3}{|c|}{ Total Losses: $(180+\chi)$ to $(276+\chi)$} \\
\hline
\end{tabular}

\#Authors' calculations, as explained in the text.

*NDTP=non-discriminatory trade policy with tariffs at present MFN rates. Gains of NDTP would be larger if trade policy were further liberalized, though the risk with a NDTP is that it may turn protectionist and be worse than a $C U$.

Fischer et al. (1994), this paper concludes that a FTA with Israel is the worst choice.

Costs and benefits of the various policies have been estimated. The estimates are only approximations because some of the underlying figures are not known with any great degree of precision and some of the costs and benefits cannot be 
estimated at all. However, the paper's conclusions do not depend on the precision of these estimates, which should be seen as providing both some orders of magnitude and some clarity to the analysis.

The paper also assumes that the issue of high transactions costs associated with security checks and border closure will have been resolved in the final status stage. This assumption seems plausible for a situation where peace has been established, is accepted by both populations and trust prevails. However, even after a formal peace agreement has been signed, reaching such a situation may take time, and until then transactions costs associated with security may be important. ${ }^{3}$ And though security aspects are important, their effect is impossible to predict with any degree of precision (except to say that lack of security will have important costs for both Israel and $W B G$ ). Nevertheless, one can say something about how changes in transactions costs affect the choice between the various trade policy options. This is done in Section 3.1.5 below.

The paper is organized as follows. Section II describes Israel's trade regime. Section III examines the effects of a customs union between $W B G$ and Israel, and similarly for a FTA in Section IV. Section V briefly discusses currency issues and Section VI concludes. ${ }^{4}$

\section{Israel's Trade Regime}

This section draws in part on the 1999 WTO Trade Policy Review for Israel. Between 1993 and 1999, the simple average of MFN tariffs fell from 8.3 percent to 7.5 percent (excluding ad valorem equivalents or $A V E s$ ). They fell in manufacturing from 8.5 percent to 7 percent, but rose in agriculture from 5 percent to 20.6

\footnotetext{
${ }^{3}$ For instance, in the case of the former Yugoslavia, Kaminski and de la Rocha (2001) show that trade among its constituent republics has so far not returned to its pre-war level, though this may also be due to the war-related destruction of productive resources.

${ }^{4}$ Panagariya and Diwan (1997) and others have also recommended, as part of a new trade policy for $W B G$, that Gaza be converted into a free port (Hong Kong-style). This paper would only stress that its success will hinge critically on a host of related policies. The establishment of a free port requires important investments, including a world-class port, warehousing facilities, communications and other infrastructure, the acquisition of specific skills, and more. The free port also requires simple and transparent rules and regulations, efficient public administration and streamlined public services. If such a policy is put into place, $W B G$ is likely to benefit. On the other hand, if transactions costs remain high due to cumbersome, non-transparent rules and widespread rent-seeking activities, $W B G$ will end up with large sunk costs and little return to show for it. This assessment seems confirmed by Rao (2000). He examined forty three free zones in the Middle East. The major reason for the poor performance of these zones is the uncompetitive and restrictive policy frameworks within which these zones operate.
} 
percent. The range of $M F N$ tariff rates increased from 0-100 percent to 0-250 percent (from 0-40 percent to 0-250 percent in agriculture, and from 0-66 percent to 0-215 percent in manufacturing). The standard deviation of the $1999 \mathrm{MFN}$ tariff (whose simple average inclusive of $A V E s$ was 8.7 percent) was 15.5 percent, reflecting a high degree of dispersion (the coefficient of variation is 1.8).

New FTA partners since 1993 include Canada, the Czech Republic, Hungary, Jordan, Poland, the Slovak Republic, Slovenia and Turkey. This is in addition to FTAs with the US, the EU and EFTA. These countries have duty-free access, mainly on industrial products. The recent FTAs go beyond trade preferences and contain provisions on trade-related aspects such as competition, state aid, intellectual property rights, safeguards, government procurement, and dispute settlement. As a result of the increasing number of FTAs, the actual average customs duties paid halved between 1993 and 1999, to a level of one percent, with 75 percent of Israeli manufacturing imports entering under preferential (mostly duty-free) rates by 1998 . The increase in the $M F N$ tariff rates on imports of agricultural products is mainly due to "tariffication," whereby non-tariff measures (such as quantitative restrictions) are replaced by equivalent tariffs, typically a first step in the process towards a more liberal trade regime. Food, beverage, clothing and footwear get higher protection.

Most imports and domestic products are subject to purchase taxes and the VAT, with some (e.g., tobacco and alcohol) subject to additional taxes. The purchase tax averages about 10 percent of the value of imports, or 10 times the average tariff rate. The VAT is 17 percent.

Israel also took additional steps to liberalize its trade regime. First, the coverage of an additional tariff called the "safeguard levy" fell from 2.7 percent of tariff lines in 1992 to 0.8 percent in 1999. Second, as a result of the Uruguay Round Agreement and the more recent International Technology Agreement, Israel bound its rates on just over half its tariff lines by 1999. ${ }^{5}$ Third, Israel has not been an active user of its anti-dumping legislation. No coutervailing or safeguard measures were taken between 1993 and 1999. ${ }^{6}$ Fourth, Israel has also improved customs valuation and has abolished the "harama" system which increased the

\footnotetext{
${ }^{5}$ However, these were often above the applied MFN rates, which maintains an element of uncertainty for investors and importers. This could be reduced by binding at applied rates and by increasing the tariff line coverage.

${ }^{6}$ These measures allow for a temporary increase in the degree of protection.
} 
value of imports by two to 10 percent before tariffs were imposed. ${ }^{7}$

With respect to non-tariff measures (NTMs), 8.5 percent of tariff lines were subject to import licenses in 1999, and 39 percent of tariff lines were subject to standards. For agriculture, the ratios were 23.5 percent and 85.8 percent, respectively, while for manufacturing, they were 7.7 percent and 37.1 percent. Thus, agriculture has been the more protected sector, both in terms of tariffs and in terms of NTMs. ${ }^{8}$

\section{A. West Bank and Gaza}

$W B G$ imports a total of $\$ 3.2$ billion, $\$ 2.4$ billion or 75 percent of which comes from Israel (all figures are for 1998). ${ }^{9} W B G$ exports a total of about $\$ 730$ million, with close to $\$ 700$ million or 96 percent exported to Israel. WBG has a GDP of $\$ 4.25$ billion (about five percent of that of Israel) and a GNP of about $\$ 5$ billion, the difference between the two being due to the Palestinian labor force that typically works in Israel (before the recent intifada). Income per capita is higher in the West Bank than in Gaza, and is about $\$ 1,700$ for $W B G$ as a whole, or about 10 percent of that of Israel.

By virtue of belonging to a $C U$, tariffs and purchase taxes on individual tariff lines are the same for Israel and $W B G .{ }^{10}$ This does not necessarily imply that average protection rates are the same because the composition of imports can differ, with one of the two having imports that are more skewed towards highprotection goods. This can be due to a different composition of goods, of source

\footnotetext{
${ }^{7}$ On the other hand, seasonal tariffs, and both MFN and preferential tariff quotas (tariff quotas provide concessional rates on imports up to a given quantity or quota), have been introduced in recent years and have reduced the transparency of the trade regime, as have a wide range of end-use provisions (granting tariff reduction for specified end-users). For some $M F N$ tariff quotas, the concessional rate is higher than the applied rate and is redundant.

${ }^{8}$ Mandatory standards are increasingly being aligned with international standards. Standards and customs valuation were amended as part of obligations Israel took under the Uruguay round. In 1999, about 25 percent of the mandatory standards were equivalent to the international ones. Israel has also made extensive commitments under the GATT, especially in the financial services area, providing legal security for market access. It is also a party to the 1997 Agreement on Telecommunications Services (Fourth Protocol), the 1997 Information Technology Agreement (ITA), and the 1997 Agreement on Financial Services (Fifth Protocol), the WTO Trade-Related Aspects of Intellectual Property Rights (TRIPS) and the WTO Government Procurement Agreement (GPA).

${ }^{9} 1998$ is the most recent year with a more complete set of trade and other figures for $W B G$. Not all imports from Israel are Israeli products, as discussed later.

${ }^{10}$ In fact, the arrangement between Israel and the $W B G$ is known as a "modified $C U$ ' because $W B G$ has access to a limited range of imports from Arab League member countries (goods on lists A1, A2 and B), whose value in 1998 was $\$ 35$ million or 1.1 percent of total WBG imports.
} 
countries, or both.

For instance, the sum of the average tariff rate and the purchase tax for Israel is about 11 percent (WTO, 2000), while it is about 16.6 percent for $W B G$ or about 50 percent higher (Astrup and Dessus, 2000). As is shown in Section 3, the higher barriers in $W B G$ associated with the different composition of imports makes the change from the $C U$ to a non-discriminatory trade policy (NDTP) more attractive to $W B G$.

The analysis of the welfare implications of a $C U, F T A$ or NDTP is based on the following assumptions. First, $W B G$ and Israel are assumed to be small open economies in the sense of taking world prices as given. Second, unless stated otherwise, the analysis assumes that goods and services are homogeneous. Schiff (1997) provides an analysis of the effects of regional agreements under these assumptions, and concludes that a small country (Country 1) is better off if it exports a lot to its partner (Country 2) and imports little from it, and if it has low tariffs and the partner has high ones. This describes the trade relations between Israel (Country 1) and WBG (Country 2). The present case is more complicated. First, $W B G$ is landlocked and most goods come through Israeli ports. Second, Israel has FTAs with the $U S$ and the $E U$. Third, smuggling takes place between Israel and $W B G$. And fourth, trade between $W B G$ and Israel is subject to high transactions costs. These conditions are explicitly incorporated in the analysis.

\section{Customs Union with Israel}

This section examines the pros and cons of maintaining a customs union $(C U)$ arrangement with Israel. It also examines ways to make the $C U$ more beneficial for $W B G$. The NDTP is used as the counterfactual relative to which the gains and losses of the $C U$ are measured. I assume that under the NDTP the same MFN tariff rates are applied as under the $C U$, and later examine the possibility of trade liberalization under the NDTP (Section III.B2).

\section{A. Losses}

There are two sources of economic losses for $W B G$ in a $C U$ arrangement with Israel. The first one consists of a loss of revenue from border taxes and the VAT associated with "indirect imports," and the second consists of a net transfer due to 
both the trade deficit with Israel and differences in average border taxes. ${ }^{11}$ The costs are first calculated relative to a counterfactual scenario of a $N D T P$ by $W B G$ vis-à-vis Israel with $W B G$ having the same trade policy as Israel vis-à-vis the rest of the world $(R O W)$, and then relative to a $N D T P$ with unilateral trade liberalization by $W B G$.

\section{A1. Tariff and Purchase Tax}

Israel charges both a tariff and a purchase tax on imports from $R O W$, including on imports that are destined for $W B G$. The $W B G$ imports from the $R O W$ that transit through Israel enter in one of two ways. They either enter as "direct imports" to $W B G$, with the $W B G$ destination of the goods clearly identified, or as "indirect imports" whose destination is declared as being Israel, and where the goods are later exported to $W B G$. The latter are typically imported by an Israeli firm, and then either re-exported to $W B G$ (possibly without the knowledge of the original importer) or purchased by Palestinians (such as those working in Israel) and taken back to $W B G$.

The tariff and purchase tax revenues on direct imports to $W B G$ are transferred by Israel to the $P A$ (less a three percent service charge) through a clearance system. This is not the case for indirect imports. Imports of $W B G$ are about $\$ 3.2$ billion (1998 figures). Direct imports from the $R O W$ were close to $\$ 800$ million ( $\$ 423$ million from FTA countries, \$35 million from Arab League members, and \$312 million from others). Imports from Israel in 1998 amounted to the rest, or \$2.4 billion. These imports include both Israeli products and indirect imports. The level of indirect imports is not known with any degree of precision. It is assumed here that they amounted to $\$ 800$ million (equal to direct imports from the $R O W$ ). ${ }^{12}$ This implies that imports of Israeli products amounted to $\$ 1.6$ billion, or half the total of imports by $W B G$.

$W B G$ captures neither the import tax revenues nor the purchase tax revenues on indirect imports (though these taxes are included in the price that $W B G$ pays for its indirect imports). The average rate of import tariff plus purchase tax on imports by $W B G$ is 16.6 percent. Thus, the loss of tax revenue (and welfare) on indirect imports from the $R O W$ equals $\$ 133$ million (16.6 percent of $\$ 800$ million) or 3.2

\footnotetext{
${ }^{11} \mathrm{~A}$ third potential source of loss relates to standards though, depending on the details of the case, it may turn out to be a source of gain. This is examined in Section III.A6.

${ }^{12}$ This figure is a "guesstimate" provided in private conversations with World Bank economists working on $W B G$.
} 
percent of GDP. This estimate is somewhat lower than that provided in $E C$ (1999) where the loss of tax revenue from indirect imports is estimated at 4 percent of GDP for 1996 and 1997, which would amount to \$160 million in $1998 .^{13}$

\section{A2. Value Added Tax (VAT)}

Israel also charges a VAT of 17 percent on imports and domestic sales. For direct imports, revenues from the VAT are transferred to the Palestinian Authority (PA). $W B G$ importers of products from Israel (either produced in Israel or indirect imports) who pay the Israeli VAT can apply for reimbursement, and if so, the VAT should not affect the price of Israeli products sold in $W B G$. However, it is likely that some leakage will take place and not all such transactions will be reported, either because the transactions costs involved are higher than the expected refund or in order to avoid paying the VAT. Estimating the importance of this phenomenon is likely to be difficult. This type of leakage is also likely to take place under a NDTP, though probably to a smaller extent because a NDTP entails border controls. Assuming that the degree of leakage under the $C U$ is 10 percent larger than under a NDTP (i.e., 10 percent of $\$ 2.4$ billion of imports from Israel, or \$240 million), the loss of revenue (and welfare) for $W B G$ would amount to 17 percent of $\$ 240$ million or $\$ 41$ million. Consequently, the loss for $W B G$ associated with the $C U$ with Israel (relative to $N D T P$ ) amounts to $\$ 174$ million so far.

\section{A3. Transfers}

The $W B G$ exports about $\$ 700$ million per year to Israel and imports $\$ 1.6$ billion of products produced in Israel, with a $\$ 900$ million trade deficit. $W B G$ experiences negative transfers on its trade in Israeli and $W B G$ products, both because of its trade deficit and because of its higher protection. The reason is as follows. $W B G$ protects its domestic output through trade taxes amounting to 16.6 percent on imports from the $R O W$. With the $C U$, Israel exports its own output to $W B G$ at zero tariff, and this implies a loss of tax revenue for $W B G .{ }^{14}$ On the other hand, given Israel's average protection of 11 percent, $W B G$ exports to Israel at a higher price

\footnotetext{
${ }^{13}$ This result would be obtained in this paper if it were assumed that indirect imports amounted to $\$ 960$ million and direct imports amounted to $\$ 640$ million, or 60 percent and 40 percent, respectively, of total foreign imports.

${ }^{14}$ The welfare gain for Israel of not paying these taxes is smaller than the loss for $W B G$ because of the inefficiency due to the trade diversion associated with the $C U$ (some of Israel's exports to $W B G$ are produced at a higher cost than the cost of importing from the rest of the world).
} 
because it does not pay the 11 percent trade taxes. This is a gain for $W B G .{ }^{15}$

Note that the 16.6 percent import tax applied at the $W B G$ border with Israel under a NDTP would not raise prices in $W B G$ if homogeneity between Israeli, $W B G$ and ROW goods and services is assumed (see below). This is because the change from the $C U$ to a NDTP does not change the level of border taxes but simply changes the location where the border tax is collected, from Israel's border with the $R O W$ to the border between Israel and $W B G$.

For two reasons (at least), these transfers are not simply obtained by multiplying the level of protection by the value of imports or exports. First, part of that trade may be in non-tradable goods and services, and prices of non-tradables are not directly affected by protection. ${ }^{16}$ Second, domestically produced goods and those imported from the partner and from the $R O W$ may not be perfect substitutes, even within the same tariff line. Under the assumption of heterogeneity, these goods are imperfect substitutes and their domestic price does not change by the full amount of the protection. Under the assumption of homogeneity, prices do change by the full amount of the protection in small open economies (including Israel and $W B G$ ).

Starting with services, exports to $W B G$ of services produced by Israel amounted to some $\$ 492$ million (out of a total of $\$ 1.6$ billion). The share of non-tradable services in these exports amounted to about 80 percent or $\$ 394$ million (see Appendix for calculations). Thus, total exports of Israeli goods and services to $W B G$ that are internationally tradable equal \$1.206 billion (\$1.6 billion - \$394 million). On the other hand, $W B G$ exports $\$ 51$ million of services to Israel. Assuming the same degree of non-tradability (of 80 percent), some $\$ 40$ million are not tradable. Moreover, $W B G$ exports stones to Israel. These are not traded internationally and amount to 11.3 percent of total $W B G$ exports to Israel, or about $\$ 80$ million. Thus, total $W B G$ exports to Israel of internationally tradable goods and services is $\$ 580$ million ( $\$ 700$ million - $\$ 120$ million).

Given these figures, and assuming first homogeneity (perfect substitutability between domestically produced goods and imports), $W B G$ loses on its imports of Israeli goods and services a total of $\$ 200$ million under the $C U$ (16.6 percent of $\$ 1.206$ billion). This is because Israel can sell at the higher price in $W B G$ due to

${ }^{15}$ This benefit for $W B G$ is somewhat smaller than the revenue loss for Israel. This is because part of the $W B G$ exports are produced at a higher cost than the cost of importing the same goods from the rest of the world (i.e., they entail trade diversion).

${ }^{16}$ Even if prices of non-tradable goods and services are indirectly affected by protection, as long as there are no distortions in the non-tradable markets, changes in their prices or output has no welfare implications. 
$W B G$ 's tariffs with the $R O W$, but $W B G$ does not collect any tariff revenue on these imports. On the other hand, it gains $\$ 64$ million (11 percent of $\$ 580$ million). Thus, the net loss is $\$ 136$ million.

Under heterogeneity, the net loss may be smaller. To compute that loss requires a general equilibrium framework as well as knowledge of--or assumptions about-elasticities of substitution in production and consumption of domestic and imported products, and this is beyond the scope of this paper. Such a framework was used by Astrup and Dessus (2000) to examine the impact of policy changes on $W B G$, and their results fall within the range of results found in this paper. Consequently, the loss for $W B G$ associated with the $C U$ with Israel is (\$174 million+ \$136 million =) \$310 million.

\section{Smuggling ${ }^{17}$}

The above assumes that the PA is able to control the border effectively and collect all border taxes. The reality, however, is that the border is extremely porous, particularly between the West Bank and Israel. Then, $W B G$ is only likely to collect part of the border taxes. Given that part of the trade taxes would not be collected under a NDTP, they cannot be counted as a loss when comparing the $C U$ with a NDTP. A leakage of 20 percent may seem reasonable, but a leakage of 40 percent is assumed here to show that a NDTP is preferable to the $C U$ even under assumptions that favor the $C U$. Thus, assuming that 40 percent of Israeli exports are smuggled and enter $W B G$ undetected, the authorities only collect 60 percent of potential trade tax revenue, or $\$ 120$ million (60 percent of the $\$ 200$ million obtained in the previous section). Some of the $\$ 80$ million of lost trade tax revenue will be wasted (in real resources spent to avoid detection) and the rest is likely to accrue to Palestinian traders and customs officials. Assuming that half the lost revenue is wasted, the welfare loss for $W B G$ associated with the $C U$ amounts to $\$ 160$ million (\$120 million of revenue plus $\$ 40$ million spent to avoid detection). Given $W B G$ 's gains of $\$ 64$ million on exports to Israel, the net welfare loss for $W B G$ is $\$ 96$ million. Thus, depending on the degree of leakage and the resources wasted in avoiding detection, the loss due to net negative transfers ranges between \$96 million and \$136 million.

\section{A4. Sum of Losses}

The sum of the WBG losses (lost revenues from tariff, purchase tax and VAT,

\footnotetext{
${ }^{17}$ For a theoretical analysis of regional integration in the case of smuggling, see Schiff (1997).
} 
and negative transfers due to the trade deficit with Israel) ranges from $\$ 270$ ( $\$ 174$ $+\$ 196)$ million to $\$ 310(\$ 174+\$ 136)$ million, or between 6.4 percent and 7.3 percent of the $G D P$ of $W B G$. In present value (with a real discount rate of, say, six percent), this loss amounts to between $\$ 4.5$ billion and $\$ 5.2$ billion, or between 106 percent and 122 percent of GDP.

Total tax revenue losses under the $C U$ amount to $\$ 334$ million in the presence of smuggling, or 7.9 percent of $G D P$, and amount to $\$ 374$ million in the absence of smuggling, or 8.8 percent of $G D P .^{18}$ Thus, replacing the $C U$ with a NDTP should enable the $P A$ to significantly lower border or other taxes without loss of revenue, and this should result in additional welfare gains.

\section{A5. Transactions Costs}

One issue not examined so far is the impact of transactions costs. What follows is not an analysis of the impact of a reduction in transactions costs per se (on that, see Astrup and Dessus, 2000). Rather, the analysis deals with how a reduction in transactions costs affects the comparison between the $C U$ and a NDTP. Calculations are presented under the assumption that smuggling does not take place. Conclusions are the same under the assumption of smuggling. If transactions costs were reduced in the final status stage, trade between Israel and $W B G$ would be larger. The non-intifada transactions costs on exports from $W B G$ to Israel have been estimated at 35 percent (Astrup and Dessus, 2000). Those from Israel to $W B G$ are smaller, and it is assumed here that they amount to 15 percent.

Assume that in the final status stage, transactions costs are reduced to five percent for trade in both directions between Israel and $W B G$. This implies that the net price obtained by Israeli exporters would be 95 (100-5) percent rather than 85 (100-15) percent of the price in $W B G$, which amounts to an increase of 11.8 percent. Assuming an elasticity of supply of Israeli exports to $W B G$ equal to one, Israeli exports of internationally tradable goods to $W B G$ under lower transactions costs would be $\$ 1.348$ billion rather than $\$ 1.206$ billion, and the $W B G$ loss from the $C U$ (of 16.6 percent) would be equal to $\$ 224$ million rather than $\$ 200$ million, or an increase of $\$ 24$ million. The net price for Palestinian exporters would be equal to 95 (100-5) percent rather than 65 (100-35) percent of the export price, which amounts to a 46.2 percent increase. With the same supply elasticity for

${ }^{18}$ Total tax revenue losses are larger by $\$ 64$ million because the positive transfer of $\$ 64$ million (associated with the fact that $W B G$ does not pay trade taxes on its exports to Israel) accrues to exporters and not to tax or customs authorities. 
exports from $W B G$ to Israel, $W B G$ exports would be equal to $\$ 848$ million rather than $\$ 580$ million, and the gain (of 11 percent) would amount to $\$ 93$ million rather than $\$ 64$ million, or an increase of \$29 million. The net effect would be \$5 (\$29 - \$24) million.

Thus, the net loss of the $C U$ under lower transactions costs would be $\$ 131$ million rather than $\$ 136$ million, or a difference of less than four percent. Assuming an elasticity of export supply of two rather than one results in a net welfare loss of the $C U$ of $\$ 126$ million. And assuming that transactions costs for $W B G$ fall only to 10 percent rather than to five percent raises the welfare loss from $\$ 136$ million to $\$ 140$ million with an elasticity of one, and to $\$ 144$ million with an elasticity of two. In other words, the reduction in transactions costs does not have a significant impact on the welfare comparison between the $C U$ and a NDTP. The reason is that the reduction in transactions costs is larger for the $W B G$ but the value of Israeli exports as well as the $W B G$ border taxes are larger, and the two sets of effects approximately cancel each other out.

\section{A6. Standards}

Israel imposes various standards on imports into the $C U$ ( 39 percent of tariff lines were subject to standards). These are imposed partly for the public good (such as sanitary and phyto-sanitary standards in agriculture, and technical standards in industry) and partly as a protectionist device (and the two sets of standards typically overlap). Both may result in costs for $W B G$. The optimal level of the public-good standards is in part a function of the income of the society that imposes them. These standards are likely to be set at levels that are close to optimal for Israel but may be too high for $W B G$ (whose per capita income is only 10 percent of that of Israel). Second, the protectionist standards are imposed to protect Israeli industry and not for the benefit of $W B G$. Under a NDTP, WBG would be able to impose standards that suit its needs. On the other hand, there is a risk that the $P A$ might use standards as a tool for protection of some of its own inefficient sectors, thereby doing more harm than good. Consequently, one cannot determine a priori whether $W B G$ standards will be better than Israeli ones.

\section{B. Benefits}

There are two types of benefits from a $C U$, one associated with avoiding the cost of establishing and managing alternative trade arrangements with Israel, and the second dealing with issues of political economy. 


\section{B1. Customs Administration}

With a $C U, W B G$ avoids the costs associated with setting up customs borders (training personnel, building customs posts, buying computers), and collecting taxes to reflect differences in VAT, excise taxes and tariff rates on third-party trade. The operating cost has been reported to amount to 1.5 percent of the value of imports (Daoud, 2000, p. 21). At $\$ 3.2$ billion of imports, this amounts to savings of $\$ 48$ million. Thus, the net loss of the $C U$ so far is $\$ 262$ million ( $\$ 310$ million - $\$ 48$ million) or 6.1 percent of GDP in the absence of smuggling, and $\$ 222$ million ( $\$ 270$ million - $\$ 48$ million) or 5.2 percent of GDP in the presence of smuggling.

The $\$ 48$ million is the cost of subcontracting customs operations to a private firm. Daoud (2000, p. 21) estimates the cost of five commercial and five passenger stations to be about half the cost of the privatization solution. Whether the former will do the job, given the border's high degree of porosity, is an open question. Daoud argues that the private solution, though more expensive, will reduce leakages and the losses of revenue associated with customs personnel's lack of experience (and possible lack of rigor in enforcing customs regulations).

Another important cost that is being avoided with the $C U$ is the lost income suffered by traders due to delays at the border. This cost can be minimized under a NDTP by lowering $M F N$ tariffs, simplifying the tariff structure and making it more uniform. This would also reduce the discretionary power of customs authorities and would reduce the lobbying and corruption that complex tariff structures typically entail. This is examined in Section III.B2 below.

\section{B2. Political Economy}

A $C U$ with Israel takes trade policy mostly out of the hands of the $P A$. Though this entails a loss of sovereignty as compared with an FTA or a NDTP, it may generate economic benefits. This depends on three issues: i) the $C U$ 's trade policy, ii) the trade policy that would prevail in $W B G$ in the absence of a $C U$, and iii) the resources spent to generate such a trade policy.

Israel's trade policy has been liberalized in recent years, with an average $M F N$ tariff of seven percent in 1999 and an overall average tariff of one percent, and import licenses on only 8.5 percent of tariff lines. The $C U$ 's external trade policy could benefit from further liberalization, though it is quite liberal and has been liberalizing. Moreover, since $W B G$ 's net trade with Israel is weighted towards agricultural goods, it should benefit from the higher protection provided to agricul- 
ture (for a given average protection rate). And though it is possible that $W B G$ might benefit from a better trade policy under an alternative arrangement, this is by no means certain. This brings us to the second and third points.

The $P A$ has the choice, under a NDTP with respect to Israel, either of implementing a better trade policy than that of the $C U$ or not. An important question is whether the $P A$ will be strong enough, and whether $W B G$ will have sufficientlydeveloped supporting public institutions with the right kind of incentive structure, in order to make decisions for the long-term benefit of the entire population rather than for the short-term benefit of particular groups. Institutions in $W B G$ are currently weak and transparency in public affairs is limited. And a number of centers of economic and political power are likely to continue exerting pressure on any future government in order to obtain favors through the political system rather than through the market. All these make it seem doubtful that the political economy equilibrium will result in a liberal and transparent trade policy. Thus, the outcome under a NDTP may very well be a more restrictive and distorted trade policy than the one under a $C U$ with Israel. ${ }^{19,20}$

Moreover, such a trade policy is likely to be the (equilibrium) outcome of the investment of real resources in the lobbying effort of different groups in order to obtain the type of protection that favors them. Thus, not only is there a danger that the trade policy itself will be harmful to the economy of $W B G$, but the process of reaching such a policy may also result in a significant waste of scarce resources.

The discipline imposed on the trade policy of $W B G$ that results from a $C U$ with Israel may well be the major benefit of maintaining the present trade arrangement. Take for instance the case of Botswana, a member of the Southern African Customs Union (SACU), which has been the fastest growing country in Sub-Saharan Africa in recent years. Botswana's trade policy is determined by South Africa. And though South Africa's past protectionist trade policy was much worse than the one presently pursued by Israel, the arrangement led to rapid growth in Botswana by taking trade policy out of the hands of its government and interest groups, and allowing all energies to concentrate on using market activities rather

\footnotetext{
${ }^{19}$ Any policy makers - whether the PA or others--face pressures from interest groups. The point, however, is that the PA is weak and its functioning is not transparent or subject to control by elected representatives, and policy outcomes will not necessarily satisfy the public good.

${ }^{20}$ Israel allows $W B G$ to import limited quantities of certain goods from Arab countries that are on lists A1 and A2. EC (1999) reports that monopolies have been created in $W B G$, partly in response to these quotas. Such an outcome is by no means inevitable as the quotas could be auctioned in a competitive environment.
} 
than the political system to generate income.

\section{Conclusion on $C U$}

The analysis has shown that a NDTP with the same structure of trade taxes as the $C U$ is superior to the $C U$. Whether the $P A$ has total control of its border or not, the loss from the $C U$ relative to a NDTP is important. That loss would be significantly reduced if revenues from border taxes were shared more equitably under an alternative system (such as on a macroeconomic basis à la $S A C U$ ).

In fact, welfare under a NDTP could be raised further by unilaterally lowering the level of trade taxes and rationalizing them. For a very small open economy such as $W B G$, lowering $M F N$ tariffs would unambiguously improve efficiency and raise welfare. However, moving to a NDTP runs the risk that the trade regime resulting from political economy forces could be highly protectionist. ${ }^{21}$ Thus, a "conditional NDTP" where trade policies are constrained to be liberal is likely to be superior to a $C U$, though a protectionist $N D T P$ may well be worse.

If the present overall $C U$ framework is maintained, it will require several changes. First, as was noted above, $W B G$ experiences losses both in terms of tax revenue on imports from the $R O W$ and from transfers due to its trade deficit with Israel. On tax revenue, one option is to improve the implementation of a notional border, with better labeling and other means of identifying the goods whose final destination is $W B G$. However, given the porosity of the border described earlier (including daily movement of Palestinian workers), a preferable option may be the sharing of import taxes on a macroeconomic basis.

A system of sharing import taxes on a macroeconomic basis has been used by $S A C U$. South Africa collects all of SACU's border taxes and shares them with the other members of SACU (Botswana, Lesotho, Namibia and Swaziland). The share of border taxes given to South Africa's $S A C U$ partners corresponds to each partner's share in $S A C U$ 's $G D P$, multiplied by a coefficient larger than one in order to compensate them for the fact that $S A C U$ 's trade policy corresponds to South Africa's priorities rather than to theirs. However, note that the fact that trade policy is determined exclusively in South Africa is also likely to generate some benefits for the partner countries by saving on resources that would have spent on lobbying for trade protection.

\footnotetext{
${ }^{2}$ The evidence from other newly independent states is not very reassuring with respect to the quality of governance. This is true of most developing countries that became independent following decolonization as well as for many of the republics of the former Soviet Union.
} 
Second, $W B G$ experiences a real income loss due to its trade deficit with Israel (and higher average tariff). One solution is for Israel to reimburse $W B G$ for an estimate of the losses. This type of arrangement has occurred in $C U s$ where the distribution of gains and losses was deemed to be asymmetric and threatened the survival of the $C U$. In fact, $C U$ s in Africa, Latin America and Asia collapsed in the past because a favored member refused to renegotiate the distribution of gains and losses. ${ }^{22}$ Another alternative would be for Israel to lower its purchase tax. This would also help with the loss associated with the tax revenue problem. ${ }^{23}$

One final issue is that if $W B G$ remains in a $C U$ with Israel, it is likely to have little say with respect to its evolution. This is of course unattractive from the viewpoint of political sovereignty. However, since Israel has pursued a process of liberalization in recent years and is likely to continue to do so, the economic implications of Israeli control of the trade policy of $W B G$ need not be adverse. Kessler (Ch. 5, p. 45, in EC Report, 1999) argues that Israeli protection probably meets Palestinian needs relatively well, with most imports from EU, US and EFTA entering duty free, and low MFN tariffs on inputs, raw materials and investment goods, and higher tariffs and NTMs on consumer goods. On the other hand, it is unclear whether Israel's standards are favorable to $W B G$. And the $C U$ also imposes a cost on $W B G$ by limiting its trade with members of the Arab League.

\section{Free Trade Agreement (FTA) with Israel}

The FTA option is first compared to a NDTP and then to the $C U$ (Section IV.D). Under a $F T A, W B G$ would establish border controls, and taxes on its imports from

\footnotetext{
${ }^{22}$ For instance, this occurred in the 1960s with the EAC (East African Community) which fell apart because Tanzania and Uganda were dissatisfied with the transfers accruing to Kenya; and the same occurred in the 1960s when Honduras left the CACM (Central American Common Market) in reaction to El Salvador's refusal to renegotiate the distribution of tariff revenues. This problem was also a factor in the war in the 1970s between East Pakistan (now Bangladesh) and West Pakistan (now Pakistan), and in the US Civil War between the North and the South (Schiff and Winters, 2003; World Bank, 2000). ${ }^{23} W B G$ uses the Israeli currency (NIS) for most of its transactions, though not as a reserve currency. If $W B G$ had a $C U$ with Israel that included a better distribution of revenues from trade taxes, its relationship to Israel would resemble the one that existed between Luxembourg and Belgium. These two countries were members of a monetary union with Belgium having a monopoly on monetary policy (still true until January 1, 2002), and they were members of a customs union (with the Netherlands). Another similarity is that Luxembourg is landlocked and part of its imports came through the ports of Antwerp and Rotterdam, so that the reimbursement of trade taxes was also an issue. The arrangement seems to have worked for Luxembourg. Of course, Luxembourg has the advantage of having large, rich and open neighbors, which, as Vamvakidis (1998) has shown, has a strong impact on a country's growth, and it has benefited from serving as a tax haven.
} 
the $R O W$ would be collected by the $P A$ rather than by Israeli authorities.

\section{A. Benefits}

A NDTP was shown in Section III to be superior to the $C U$ (assuming $W B G$ 's freedom under a $N D T P$ to set its own trade policy does not result in closing the economy). A NDTP is also superior to an FTA for two reasons at least. First, the net negative transfer ranging between $\$ 96$ million and $\$ 136$ million under the $C U$, and which is associated with $W B G$ 's trade deficit with Israel, remains under an FTA but not under a NTDP because, in the latter case, tariffs would be collected on trade with Israel. Second, a NTDP does not require rules of origin (and neither does a $C U$ ), and these can be very costly for the authorities as well as for traders and for the economy as a whole.

\section{B. Rules of Origin (ROO)}

Replacing the $W B G$-Israel $C U$ with an $F T A$ requires $W B G$ to establish border controls. These controls entail a number of significant costs, including the establishment and operation of a customs administration. These costs are also incurred under a NDTP. However, one of the customs administration principal activities under an FTA is the control of the origin of goods exported by Israel to $W B G$. This is required in order to avoid the problem of trade deflection, particularly if $W B G$ has higher tariffs than Israel under the FTA, given that most imports from third countries come through Israeli ports.

Under trade deflection, $W B G$ would lose control over its external trade policy, with the effective tariff on goods imported by $W B G$ equal to the lower Israeli tariff. Moreover, $W B G$ would not even collect the revenue associated with that lower tariff because the firms importing the goods would be paying the lower tariff to the Israeli customs authorities. WBG would then be better off adopting the lower Israeli tariff because this would eliminate any incentive for trade deflection and $W B G$ would at least collect the tariff revenue associated with the lower tariff.

Ideally, an FTA should entail the free movement of value added produced inside the bloc. However, trade takes place in final goods and not in value added. Consequently, rules of origin ( $R O O$ ) have been devised in order to (imperfectly) control for the origin of goods. The attempt to solve the problem of trade deflection through $R O O$ results in a number of new problems. ${ }^{24}$ First, $R O O$ can lead to

${ }^{24}$ Most of these problems are examined in Krueger (1997). 
additional trade diversion and a welfare loss. Second, $R O O$ are typically quite complex and enforcing them can be very costly for the authorities but even more so for exporters. The book that describes NAFTA's ROO is 200 pages long. Enforcing such complex rules entails a variety of additional costs, over and above the standard costs of customs administration in the case where $M F N$ tariffs apply to all countries.

Third, proving origin (including obtaining all the necessary documents) can be very costly for exporters as well. These costs have been estimated by Herin (1986) at three to five percent of the f.o.b. price for EFTA countries. In $W B G$, a poorer region with less experience in customs administration, costs of border delays are likely to be larger than in EFTA countries. Given WBG's FTAs with Israel, the $E U$ and the $U S$, imports from FTA regions would amount to about $\$ 2.8$ billion. With compliance costs for exporters estimated at three to five percent of imports, the cost would be equal to $\$ 84$ to $\$ 140$ million. Astrup-Dessus (2001) estimate the loss due to $R O O$ at 2.8 percent of welfare (i.e., of $G D P$ of $\$ 4.25$ billion) or $\$ 140$ million. Including this cost reduces the net benefit of the FTA to something close to zero.

Fourth, $R O O$ are typically used as protectionist devices. This further restricts the free movement of goods between partners. Thus, producers in $W B G$ might insist on restrictive $R O O$ to prevent competition from cheaper Israeli imports. Restrictive $R O O$ will reduce the degree of competition in $W B G$ and will reduce the duty-free access of $W B G$ exports to Israel.

Fifth, Israel has an FTA with Jordan and $W B G$ is also likely to consider having one in the final status stage. Moreover, $W B G$ has FTAs with the $U S$ and the $E U$ (and with Turkey because it has a $C U$ with the $E U$ ), and may have more FTAs in the final status stage (following Israel's example which has FTAs with various Central and Eastern European countries). An independent trade policy implies establishing $R O O$ for each and every one of the FTAs. This is likely to result in a "spaghetti bowl" (which originally referred to overlapping FTAs in Latin America). These overlapping FTAs are likely to greatly complicate the administration of $R O O$ for $W B G$ and to greatly increase their cost. An FTA with Israel will further complicate the management of $R O O$.

The various points enumerated above indicate that $R O O$ can be very costly, especially for a small economy like $W B G$ that needs foreign markets to grow. From that viewpoint alone, an FTA with Israel is less desirable than a NDTP. If one only includes the cost to exporters of establishing the origin of their goods, which 
ranges from $\$ 84$ million to $\$ 140$ million, and the negative transfers, which range from $\$ 96$ million to $\$ 136$ million, the benefit of a NDTP relative to an FTA ranges from $\$ 180$ million to $\$ 276$ million, or from 4.2 percent to 6.5 percent of GDP. And this does not include the other FTA costs associated with $R O O$ (denoted by the letter " $x$ " in Table 1).

\section{FTA with Jordan}

What about an FTA between $W B G$ and Jordan ? Such an FTA will require rules of origin, and the costs associated with those may be large, as examined in Section IV.B. Moreover, Jordan has been liberalizing its economy, so that $W B G$ is unlikely to gain more from any preferential access to Jordan than it will lose from giving preferential access to Jordan in its own market.

\section{FTA with Israel versus $C U$}

The analysis so far has shown that a liberal NDTP is superior to the $C U$ and to an FTA. What about the comparison between an FTA and the $C U$ ? Border taxes and the VAT on indirect imports will be collected under an FTA but not under the $C U$, amounting to a gain of $\$ 174$ million for the former. On the other hand, an FTA will require border controls and customs administration, whose operating cost (not including any setup cost) has been estimated at \$48 million. An FTA will also require $R O O$. The cost to exporters of establishing origin has been estimated at between $\$ 84$ million and $\$ 140$ million. Thus, the net gain of an FTA relative to a $C U$ ranges from $\$ 42$ million to negative $\$ 14$ million, which averages to $\$ 14$ million or some 0.3 percent of GDP.

However, this does not include other important costs associated with $R O O$. These include the trade diversion and welfare loss typically associated with $R O O$ (a major problem for a very small economy like $W B G$ that needs to obtain many of its inputs from the $R O W$ ), the tendency of the $R O O$ to become a protectionist device (with additional welfare losses), and the cost of administering the ROO. Thus, the $C U$ with Israel is preferable to an $F T A$, once all the costs associated with the FTA are taken into account.

\section{E. Conclusion on NDTP, FTA or $C U$}

The analysis leads to the following trade policy recommendation:

The PA should pursue a non-discriminatory trade policy (NDTP) with all its neighbors, but only under the condition of an open and transparent trade policy 
enforced by credible lock-in mechanisms. Otherwise, a CU with Israel is likely to be preferable.

\section{Currency}

The issue of currency choice is only briefly examined here. A more detailed analysis is found in Kleiman (1999), though the proposals considered differ somewhat. Currency is one of the basic symbols of national sovereignty. It can provide economic benefits but it carries important risks. One risk is that a government would make use of the printing press to finance fiscal deficits caused by pressures for additional spending from a variety of interest groups, thus resulting in inflation.

The $W B G$ uses the New Israeli Shekel (NIS) for most transactions. The seigniorage on that accrues to Israel. This is a loss for $W B G$ which has been estimated by $E C$ (1999) at $\$ 50$ million or one percent of GNP (calculated at the interest rate on Israeli government bonds). One possibility is for Israel to compensate $W B G$ for this loss. On the other hand, as argued by Depres et al. (1966) for the US dollar, Israel could argue that $W B G$ benefits from Israel monetary policy and the stability of the NIS (relative to a currency managed by the PA) and that this facilitates domestic transactions as well as trade and other transactions with Israel, its main trading partner.

On the other hand, and for obvious reasons, it is likely to be politically unfeasible to use the NIS in $W B G$ in the final status stage. An alternative is to replace it with a major currency, such as the $U S$ dollar, which is already used by Palestinians as a reserve currency. Precedents of countries that have adopted the US dollar as their currency include Ecuador and El Salvador. Another alternative is the euro. If it performs satisfactorily (with respect to the dollar), and given that the $E U$ is the largest trading partner of $W B G$ after Israel, the euro might have to be considered as another alternative.

An intermediate solution (between the choice of NIS and a major currency), though possibly not altogether satisfactory to the Palestinians, is to use the NIS but with different symbols on the notes. This solution has been applied by the United Kingdom in the case of Scotland where the British Pound circulates but with Scottish rather than English symbols. ${ }^{25}$

${ }^{25}$ Thanks are due to Peter Robson for providing this information. 


\section{Concluding Comments}

This paper examined various options regarding the trade policy of $W B G$ in the final status stage. It concludes that a non-discriminatory trade policy is likely to be superior to a $C U$ with Israel, and the $C U$ is likely to be superior to an FTA with Israel. But there is an important caveat. Replacing the $C U$ with a nondiscriminatory trade policy must entail an open, liberal trade regime with low, uniform tariffs bound at the WTO at the applied rates, and the implementation of a credible mechanism to constrain the use of protectionist non-tariff measures. The paper also recommends that $W B G$ pursue an open non-discriminatory trade policy with respect to Jordan.

More generally, a newly independent Palestinian state has the choice of becoming an open, market-oriented, competitive and dynamic economy, with a government enforcing simple, transparent and uniform rules that apply to all. This will enable the entire population to share the fruits of economic growth. The alternative of a government subject to successful rent-seeking activities and providing special favors to various interest groups is likely to result in economic stagnation, with negative consequences for the stability and the well-being of $W B G$ and the region as a whole.

\section{Acknowledgement}

This paper considers regional and unilateral trade policy options for the West Bank and Gaza $(W B G)$. It examines the welfare implications of a free trade agreement (FTA) with Israel, a customs union $(C U)$ with Israel, and a non-discriminatory trade policy $(N D T P)$. The analysis captures the fact that the $W B G$ is landlocked, that it has a large trade deficit with Israel, and that smuggling takes place between them. The paper concludes that i) a NDTP is unambiguously superior to a FTA with Israel; but ii) the $W B G$ should only pursue a NDTP if the policy is open, transparent, and enforced by a credible lock-in mechanism; otherwise, a $C U$ with Israel may be preferable, especially if trade and other taxes are shared more equitably. 


\section{References}

Astrup, Claus and Dessus, Sebastian (2001) Trade Options for the Palestinian Economy: Some Orders of Magnitude. Middle East and North Africa Region, World Bank (February), Washington, D.C.

Economic Community (1999) Evaluating the Paris Protocol. Economic Relations between Israel and the Palestinian Territories. Brussels (July).

Daoud, Yousef S. (2000) Revenue and Direct Cost Implications of a Policy Switch to an FTA. Paper prepared for PECDAR (September).

Depres, E., Kindleberger, C. and Salant, W.S. (1966) The Dollar and World Liquidity. A Minority View, The Economist (February 5).

Fischer, Stanley, Hausman, Leonard J., Karasik, Anna D. and Schelling, Thomas C. (eds.). 1994. Securing Peace in the Middle East. MIT Press: Cambridge and London.

Herin, J. (1986) Rules of Origin and Differences between Tariff Levels in EFTA and in the EC. EFTA Occasional Paper No. 13. Geneva (February).

Kessler, Veronique (1999) Palestine's External Trade Performance Under the Paris Protocol: Hopes and Disillusions. Chapter 5 in European Commission, op. cit.

Krueger, Anne O. (1997) Free trade agreements versus customs unions, Journal of Development Economics 54, 169-187.

Kaminski, Bartolomiej and de la Rocha, Manuel (2001) EU Stability and Association Framework: Implications for Trade Policies. Mimeo, DECRG, World Bank.

Kleiman, Ephraim (1999) Evaluating the Fiscal and Monetary Arrangements of the Paris ProtocolóA Counterfactual Analysis. Chapter 7 in European Commission, op. cit.

Panagariya, Arvind and Diwan, Ishak (1997) Trade Policy Options for the West Bank and Gaza Strip. Palestine Economic Policy Research Institute (MAS) Discussion Paper, Jerusalem, and World Bank, Washington, D.C. (January).

Rao, Kishore (2000) Free Zones in the Middle East: Development Patterns and Future Potential, Chapter 11 in B. Hoekman and H. Kheir-El-Din (eds.) Trade Policy Developments in the Middle East and North Africa. World Bank. Washington, D.C.

Schiff, Maurice (1997) Small is Beautiful: Preferential Trade Agreements and the Impact of Country Size, Market Share, and Smuggling, Journal of Economic Integration 12(3), 359-87.

Schiff, Maurice and L. Alan Winters (2003) Regional Integration and Development. Oxford University Press: Oxford.

Vamvakidis, Athanasios (1998) Regional Integration and Economic Growth, World Bank Economic Review 12(2), 251-270.

World Bank (2000) Trade Blocs. A Policy Research Report. Washington, D.C.

WTO (1999) Trade Policy Review, Israel. Geneva. 


\section{Appendix}

West Bank-Gaza Imports of Services from Israel (\$000, 1998)*

\begin{tabular}{llcc}
\hline & & Total & Tradable \\
\hline P-E & Electricity, gas, water supply & 138,604 & - \\
P-F & Construction & - & - \\
P-G.5020 & Maintenance and repair of motor vehicles & 296 & - \\
P-G.5050 Retail sale of automotive fuel & - & - \\
P-G.50R & Sale of motor vehicles and parts & - & - \\
P-G.51 & Wholesale & - & - \\
P-G.5260 Repair of personal and household goods & 2,362 & - \\
P-G.52R & Other retail sale & - & - \\
P-H & Hotels, restaurants & 61,548 & 30,774 \\
P-I & Transport, storage, communications & 88,159 & 44,080 \\
P-I.6411 & National post activities & 1,069 & - \\
P-I.64R & Remaining communication & 45,399 & 22,700 \\
P-J.6511 & Central banking & - & - \\
P-J.6519 & Other monetary intermediation & 46 & - \\
P-J.660 & Insurance, pension funding, except compulsory social security & 12,017 & - \\
P-J.R & Other fin. interm., auxiliary activities & - & - \\
P-K & Real estate, renting, business activities & 69,436 & - \\
P-L & Public administration, defence; compulsory social security & 28,924 & - \\
P-M & Education & 7,867 & - \\
P-N & Health, social work & 31,518 & - \\
P-O & Other community, social, personal service activities & 4,490 & - \\
P-P & Private households with employed persons & - & - \\
\hline & Total & 491,734 & 97,554 \\
\hline
\end{tabular}

*The calculation of tradables assumes that half of categories P-H, P-I and P-I.64R consist of tradables. 